\title{
Cardiac Myxoma in a Case of Carney Complex
}

\section{${ }^{1}$ Gauranga Majumdar, ${ }^{2}$ Surendra Agarwal, ${ }^{3}$ Shantanu Pande, ${ }^{4}$ Bipin Chandra, ${ }^{5}$ Prabhat Tewari}

Keywords: Myxoma, Carney complex, Echocardiography, Surgical excision, Cardiac myxoma.

How to cite this article: Majumdar G, Agarwal S, Pande S, Chandra B, Tewari P. Cardiac Myxoma in a Case of Carney Complex. World J Endoc Surg 2014;6(3):127-128.

Source of support: Nil

Conflict of interest: None

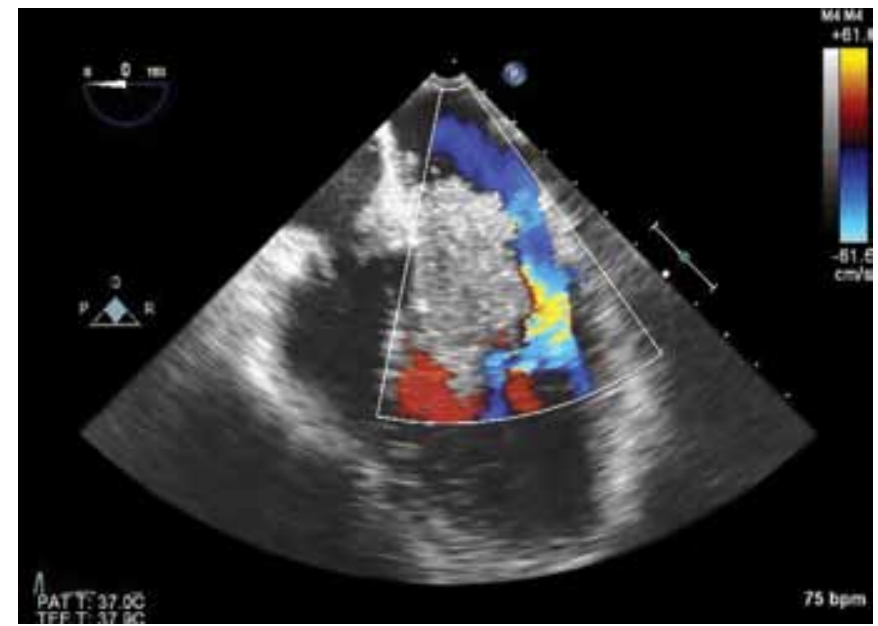

Fig. 1: Transesophageal echocardiography image showing left ventricular inflow and outflow pathway. Mitral valve is open and large left atrial tumor arising from intra-atrial septum prolapsing into LV cavity in diastole. Blue jet indicates narrowed LV inflow and red indicates left ventricular outflow tract (LVOT) outflow

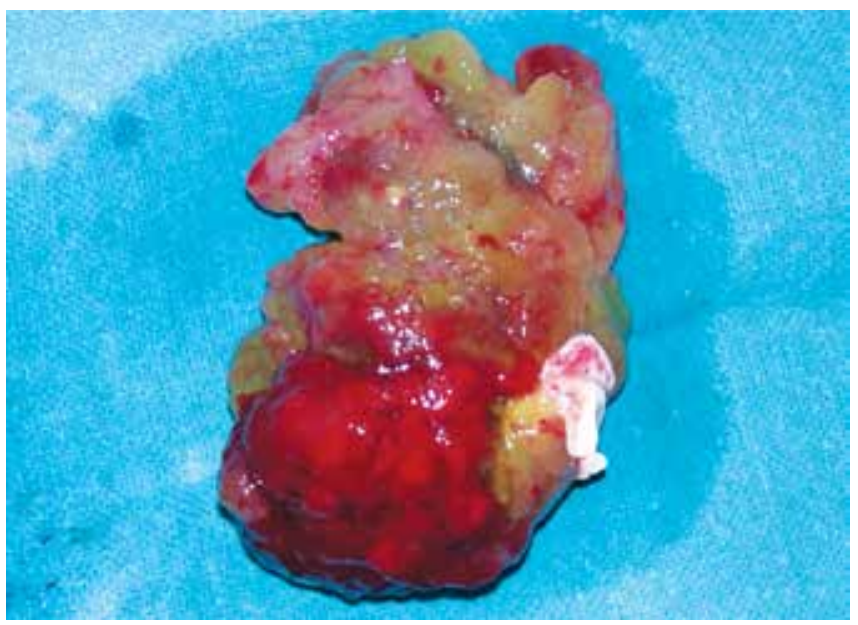

Fig. 2: Excised large left atrial myxoma along with pedicle interatrial septal tissue

The complex of myxoma, spotty skin pigmentation and endocrine over activity or Carney's complex (CNC) is an autosomal dominant disorder that was described in 1985 by Carney. ${ }^{1}$ We are presenting a rare image (Fig. 1: echocardiography, Fig. 2: excised surgical specimen) of left atrial myxoma in a case of Carney's complex in a young patient who was successfully treated in our institution. A 22 years old male presented with features of Cushing disease, revealed adrenocorticotropic hormone (ACTH) independent hypercortisolism on laboratory investigation. A magnetic resonance imaging (MRI) was done which showed pituitary macroadenoma and bilateral adrenal tumor. A screening 2D echocardiography followed by transesophageal echocardiography (TEE) (Fig. 1) revealed a large left atrial tumor arising from interatrial septum and moving with anterior mitral leaflet and prolapsing into left ventricle. In presence of cardiac myxoma, pituitary adenoma and adrenal hyperactivity, a diagnosis of Carney's complex was made. Approximately, 30 to $60 \%$ of Carney's patients will develop cardiac myxoma, ${ }^{2}$ usually at much younger ages than the sporadic tumors. As a cardinal feature of $\mathrm{CNC}$, cardiac myxoma is responsible for the death of more than $50 \%$ of patients, either from tumors themselves or from postsurgi-

\footnotetext{
${ }^{1,4}$ Associate Professor, ${ }^{2,5}$ Professor, ${ }^{3}$ Additional Professor

${ }^{1-4}$ Department of Cardiovascular and Thoracic Surgery, Sanjay Gandhi Postgraduate Institute of Medical Sciences, Lucknow Uttar Pradesh, India

${ }^{5}$ Department of Anesthesiology, Sanjay Gandhi Postgraduate Institute of Medical Sciences, Lucknow, Uttar Pradesh, India
}

Corresponding Author: Gauranga Majumdar, Associate Professor, Department of Cardiovascular and Thoracic Surgery, Sanjay Gandhi Postgraduate Institute of Medical Sciences, Lucknow, Uttar Pradesh, India, Phone: 05222494204, e-mail: gaurangamajumdar@ hotmail.com 
cal complications. ${ }^{3}$ Surgical removal of intracardiac tumor under cardiopulmonary bypass support is mainstay of treatment. Surgical management was performed in two stages, atrial myxoma was removed (Fig. 2) in first stage and, after 4 weeks, laparoscopic bilateral adrenalectomy was done as second stage. Follow-up with echocardiography after 1 year showed no recurrence.

\section{REFERENCES}

1. Carney JA, Gordon H, Carpenter PC, Shenoy BV, Go VL. The complex of myxomas, spotty pigmentation, and endocrine overactivity. Medicine (Baltimore) 1985;64(4):270-283.

2. Bertherat J. Carney complex (CNC). Orphanet J Rare Dis 2006 Jun 6;1:21.

3. Stratakis CA, Kirschner LS, Carney JA. Clinical and molecular features of the Carney complex: diagnostic criteria and recommendations for patient evaluation. J Clin Endocrinol Metab 2001 Sep;86(9):4041-4046. 